\title{
Ingenuity in Isolation: Poland in the International History of the Internet
}

\author{
Christopher Leslie and Patrick Gryczka \\ New York University Polytechnic School of Engineering, Brooklyn, NY, USA \\ \{chris.leslie, pg1009\} @nyu.edu
}

\begin{abstract}
The popular understanding of the invention of the Internet is that it was the work of researchers in the United States working in relative isolation. However, the Internet is about connection, and so its success required the independently developed networks of the international community. By analyzing early network development in politically isolated Poland toward the end of the Cold War, one sees development concurrent to the development of the Internet but separated technologically through CoCom trade embargoes. By analyzing information technology periodicals, FidoNet newsletters, and other sources, a number of projects have been identified: data distribution over radio and the use of computer networks to protest communist propaganda. In addition to these amateur efforts, we learned about commercial products and academic research. While these efforts were not successful in a conventional sense, they do demonstrate how the computer industry and network research in Poland played an important role despite the political restrictions.
\end{abstract}

Keywords: Internet, Poland, Cold War, innovation, technology transfer, ethics.

\section{Introduction}

The Internet is popularly considered to be an invention of the United States. At the height of the dot-com boom, the myth of the American ingenuity that created the Internet in isolation was perfected: once TCP/IP was perfected for a military research network, ARPANet, it was brought to the academic world with CSNET, discovered by civilian users with USENET and other online sources, and finally distributed to the rest of the world in the 1990s via NSFNET projects (see, for instance, [1,2]). The first mention of the international community in this narrative is often Tim Berners-Lee, the British inventor of the World Wide Web.

This fable of Yankee ingenuity disregards both the global nature of the Internet community and the national infrastructural developments needed to provide the necessary intellectual and technical infrastructure for Internet technology to be widely adopted. As presented elsewhere, core concepts behind the Internet, such as packet switching, have roots in the international technical and scientific community. What is more, the Internet is about connecting networks, and a key design consideration of TCP/IP was to allow independently developed networks from the international community a means to connect [3]. It should not be controversial to state that the U.S. 
relied heavily on their counterparts in other countries to produce the flexible protocols that account for the rapid spread of the technology, and yet this story is not often told.

In addition to the direct influence of the international community, one should consider how researchers in countries who were not directly involved. The dictum that the number of Internet users reached 50 million in 4 years, while it took television 13 years and radio 38 years, may be difficult to verify - it certainly depends on which statistics one uses [4] - but there is no question that the seeds of TCP/IP fell on fertile ground. The impression that the Internet spread to many corners of the world quickly, however, should lead one to question the notion that it diffused on its own accord. As noted by in the case of the diffusion of the Internet to Israel [5], the Internet "is unable to 'march' anywhere" (327): adoption of Internet technology depends on the preparation and interest of identifiable people. This insight can be profitably applied to the analysis of technology transfer to Poland. Although it might seem that the Internet could not be diffused to Poland until after the fall of the Berlin Wall and the collapse of the Soviet Union, this would deny the active effort of individuals in Poland who prepared the way for a technology like the Internet even while they were politically separated from areas that used it.

The entry of western technology at the start of the 1990s is described as if hightech companies were entering into barren field, a rhetoric that might be expected given a world weary of the more than 40 years of standoff. A press release distributed by IBM [6] announced a grant for the creation of a "backbone of a computer network" linking 14 Polish universities "with each other and with similar networks created by IBM." The program was to include training "to increase the level of information technology skills, skills that are vital for competitive economies." Poland was described in the Wall Street Journal as leading the computerization of eastern Europe: "Entrepreneurs are starting small personal-computer dealerships, business people are equipping their firms with low-powered computers, and small companies are fighting for government software contracts" [7]. The triumphant tone is still visible in articles like [8], which notes that "changes came quickly" after the fall of the Berlin Wall. Demand for privatization in the former Soviet block along with relaxing restrictions on the export of technology brought computing to eastern Europe, and "companies that survived began modernizing" (20). From these descriptions, it seems as if there had been no computers and no networks in Poland earlier, and only through the beneficence of the victors of the Cold War was Poland able to enter the computer age.

The sensation that the countries of eastern Europe were in a state of technological depravation, while accurate in some ways, does not tell the entire story. The online magazine Pigulki snidely commented on the paragraphs of the 1991 IBM press release [6], noting "the Poles themselves have brought this network into being already, as Pigulki readers would have gathered by now" and suggesting "Big Blue was, to say the least, not among the major forces spearheading Poland's academic computer network." The foundation for the connection to the west was done by those in the hard sciences, computer systems administrators, and colleagues in the Polish diaspora [9]. With the connection to the west, there was a sudden sense of connectivity, though this apparently was more keenly felt from the outside. One researcher [10] writes, "there were [a] lot of people from the USA, Germany, the UK, and France, checking 
constantly whether PLEARN was already on line." A question he was asked in one of his first chats with someone in the U.S. was whether he could send messages without censorship from any terminal. Nevertheless, network connections had already existed.

It is true that Cold War prohibitions on high-tech exports had restricted Poland's access to the computer technology and, more specifically, to the growing community of TCP/IP users as well as other networks. What are now known as the CoCom restrictions began as part of the administration of the Marshall Plan aid to Europe in 1948. As a condition of receiving aid, recipient countries were prohibited from exporting products to non-recipients anything that the U.S. would normally disallow [11]. In this way, the U.S. hoped to prevent communist countries from mustering the strength to wage war. The Coordinating Committee for Multilateral Export Controls (CoCom for short) was set up to manage the embargo. The ban was not absolute; in a 1960 meeting to review items on the embargo, the U.S. was unsuccessful in convincing British authorities to classify digital computers as munitions subject to the embargo, asserting that the Soviet Union used computing for military purposes. In 1969, the U.S. announced new guidelines that only between 6 and 18 fast computers per year could be exported to eastern Europe (excluding the USSR). In 1984, these restrictions were tightened to include recent advances in smaller, personal computers. In a newspaper article at the time, an Assistant Secretary of Defense was cited as the source of the idea that the military uses Apple 2 computers for targeting nuclear weapons, and so proliferation of such small devices must be restricted [12]. In spite of these challenges, a number of developments, potentially unique to Poland, can be identified. Among them, a radio modem, which was developed to deal with the unreliable telecommunications infrastructure in Poland, and the use of computer networks to protest communist propaganda.

The story of Poland's ingenuity despite being isolated from international developments, taken together with other stories of the diffusion of the Internet, presents an ethical challenge. It might be simpler and more dramatic to tell the story of U.S. engineers wresting control of a military research project for the benefit of the international public. However, this story is unethical in that it suggests that innovation takes place within isolated national borders, disregarding the role of individuals outside of those borders on which innovation depends. The World Wide Web, for instance, depended heavily on the conventions of TCP/IP and the DNS that had already been designed with the engineers in different countries in mind and vetted by the international community. Without this this deep involvement with researchers outside of the United States, Berners-Lee's innovation would have remained a distributed hypertext project confined to workstations at CERN.

Documenting the projects that encourage the development of computing intellectual capital - in other words, the development of engineers and scientists who are familiar with computing concepts - is pivotal in the diffusion of technologies like the Internet. Because innovation sometimes comes from the negotiation of different technical and cultural standards, and because technical innovations fail and succeed based on a larger community of practitioners, it is unethical to assert that a small group of researchers in one country are responsible for a widespread technical achievement like the Internet. 


\section{Methodology}

In Science and Technology Studies, the concept of the user has gained increasing prominence over the past twenty years, and the study of the history of the Internet could benefit from this development. In Poland, the situation was that a user base was previously established onto which TCP/IP could easily be transmitted once the necessary political blocks were eliminated. To analyze the technical developments of early network development in Poland and the cultural influence on the network's uses, documents pertaining to the topic have been found, compiled, translated, and analyzed. By combing through numerous information technology periodicals, FidoNet newsletters, and other assorted sources, we have sought evidence of an important ethical consideration: it is not the case that a relatively isolated country like Poland was passively waiting for a connection.

Although there are no books on the topic, articles do mention Polish academic networks and personal connections to FidoNet. To find out as much as possible about the beginnings of the Internet in Poland and the early academic networks that came out of Polish universities, it seemed appropriate to look for previous works on that topic; however, it soon became evident that there were few if any published academic works on this topic in either English or Polish. Turning to the technical periodicals of the time and newsletters of early networks such as FidoNet, an enormous archive of network newsletters and newspaper and magazine articles from the time period, interesting and significant papers in Polish were found. In addition, attempts were made to email contributors to the early academic networks in order to gain firsthand information about the networks; a portion of the information gathered has been found in the university libraries and archives. Many of the technical details that were learned about the early networks were found by visiting the universities where these networks originated and reading through students' and professors' theses and works that have been written about the networks.

This documentation supports a different ethical framework that appreciates the complex interactions between innovation and diffusion of technology. In telling the story of Poland's researchers in the waning years of the Cold War, we hope this methodology demonstrates the importance of adopting different ethic of innovation.

\section{Polish Networking at the End of the Cold War}

Networking in Europe was well underway in the 1980s. One of the most visible international networking efforts began in 1983, when IBM established a counterpart to its 1981 network, BITNET, in Europe. Called the European Academic Research Network (EARN), IBM provided access to networking through a connection through Wisconsin [13]. With a connection provided by EARN, one could browse the famous Request for Comments (RFCs) distributed by the burgeoning Internet community, making people curious about its protocols even though the official policy was to wait for the formalization of OSI standards [14]. As the German Internet pioneer Claus Kalle has remarked, this connection finally gave users an experience of the Internet, 
"das man damals höchstens aus dem Kino (War Games) kannte)" (which one then at least knew from the cinema (War Games)) [15].

Through e-mail came RFCs about TCP, IP, Telnet, and FTP, from which users and learned how the new protocols could be implemented on local platforms. These efforts to use TCP/IP in Europe, however, did not extend to the Warsaw Pact countries due to an interpretation of the CoCom restrictions. In fact, the only way to users in this region were able to connect their computers was to a friendly computer on the other side of the Iron Curtain, but according to Tomasz Hofmokl this was inexpensive and unreliable, and more official solutions were not forthcoming. He writes, "I received the official refusal from the French side to establish a permanent communication line with Paris in 1987 by e-mail in Warsaw" [16].

In early 1990, when the CoCom restrictions were relaxed, countries in Eastern Europe could connect to international computer networks. A few months later, the board of directors of EARN decided to admit eastern European countries; Poland was the first, bridging the divide between Europe and former Soviet Block countries. This link was followed by Czechoslovakia and Hungary [16]. The president of EARN, Frode Greisen, visited Warsaw University to make the announcement on April 10 [10]. The symbolic date denoting the beginning of the Internet in Poland was 1990 when engineers at Instytut Fizyki Jadrowej (IFJ, the Institute of Nuclear Physics) in Krakow sent the first email from Poland. Within a few months, many connections to EARN were set up and within a year many of Poland's larger cities connected to the Internet.

As seen in Figure 1, Poland's first international link to the TCP/IP Internet was established by Naukowa i Akademicka Sieć Komputerowa (NASK, or Research and Academic Computer Network) in November 1991, with a data line of $64 \mathrm{~Kb} / \mathrm{s}$. A month later, Polish Internet traffic was then allowed into the United States network, NSFNET. In 1992, the first academic metropolitan area network (MAN) was built, which ran on fiber optic cables. That same year, a networking organization for the region, Central and Eastern European Network (CEENet) was established; it would grow to 19 members. Soon after, in 1993, ten more MANs were set up across Poland in cities with large universities. Then in 1997, these MANs were interconnected with a new broadband network. The network, POL-34, started with speeds of $34 \mathrm{Mb} / \mathrm{s}$ and was quickly upgraded in 1998 to $155 \mathrm{Mb} / \mathrm{s}$, and it was also connected to the global internet through a Swedish satellite link through Telenordia. By 2002 POL-34 had been upgraded to even faster lines and upgraded to use ATM, Gigabit Ethernet, and Cisco routers (7200, 7500, 12000 GSR). These upgrades allowed for a main line of $622 \mathrm{Mb} / \mathrm{s}$ and $155 \mathrm{Mb} / \mathrm{s}$ and $34 \mathrm{Mb} / \mathrm{s}$ branching lines. After these upgrades were completed halfway through 2002, POL-34 was connected to a new Polish academic network, the PIONIER fiber optic network [17].

The fact that Poland was the first of the Soviet Block countries to connect to the west was not an accident. This achievement, after all, was built on earlier accomplishments and the successful lobbying of members of the Polish computer science community. In spite of CoCom restrictions, manufacturers were allowed to export computers in excess of the quotas under an exceptions clause related to computers for non-military use; interestingly, Poland was the "largest designation" of exceptions at 135 cases [11]. One can assert that this embargo was effective. While, as noted by 
[18], "it is extraordinarily difficult to prove, with hard economic data, that Western export controls have held back the development of computing" in Poland and other countries of the Council for Mutual Economic Assistance (CMEA), the "causal observer" can see that eastern Europe was behind (429; emphasis in original). Nevertheless, Geipel et al. demonstrate that CMEA countries in general, and Poland in particular, made an effort to invest in computers. Investment "always either increased more or decreased less" when compared to other light industries, and the percentage of the population engaged in scientific research ranged from 0.25 to 0.45 , as compared to 0.22 in the United States.

Furthermore, Poland along with Hungary allowed private enterprise in computing starting in the $1980 \mathrm{~s}$, and at the time of the Wende there were more than 500 private computing firms in Poland. Additionally, personal computers were excluded from CoCom restrictions in the 1980 s, which meant importers were free to bring them to market. This community of personal computer users - based on ZX Spectrums, Commodore 64s and Atari 800XLs - sought to connect Poland to FidoNet, a loose organization of amateur bulletin board systems (BBSs). Jan Stozek translated FidoNet documentation into Polish in 1987 and soon a BBS was set up in the offices of Komputer magazine [19]. This publication covered modems and FidoNet, and the community began to grow. Region 48 was assigned to Poland by a Dutch computer club official of Polish descent, and it would be the first region in the Soviet Block. The following year, Stozek would become the network coordinator in Poland. By 1991, there were 15 BBSs operating in Poland, most of which were set up at private companies by individuals who convinced their superiors that such a service would support their commercial activity. One BBS was located at the University of Poznan, where Zbyszek Borowiec was able to transfer messages to BITNET before PLEARN was established.

Poland's readiness to accept international data was also facilitated by earlier work in networking. Because these networks used X.25, it was simpler to make the connection; Smereczynski, who set up the Polish node of EARN, PLEARN, notes that the "constrained isolation" of networking in Poland in the last years of the Cold War helped to show how a network could be formed in adverse conditions. "The main achievement of the KASK project," he writes, "was the experience of showing that you cannot ignore the international standards, or your project would fail" [10]. Smereczynski's tone is one of despair concerning the state of computer science in Poland, but this is clearly from his perspective as someone who could see the future potential. For instance, he was not positive in his recounting of IBM's support; he recollects several experiences with IBM equipment that was late and delivered with software full of bugs, and the first connection to EARN was actually made on an IBM clone, a BASF 7/38 with Hitachi components. This alone demonstrates his effectiveness in dealing with less than optimal conditions. Likewise, Smereczynski notes that there were many people in the Polish computer science community that did not know what it meant to send email or to join into an international network, and so he and his colleagues set up seminars on EARN, e-mail, Listerv, and fundamentals of networking commands, or "just enough to introduce people to EARN networking." The fact that there was a technical community ready to undergo this training, and individuals from Poland ready to offer it, makes it clear the active role the local community played in the diffusion of this technology. 


\begin{tabular}{|c|c|}
\hline 1971-1973 & $\begin{array}{l}\text { Development of the K- } 202 \text { computer, a Polish minicomputer, } \\
\text { which was the basis of the MERA } 400 \text { system produced later } \\
\text { in the decade. }\end{array}$ \\
\hline 1977-1978 & $\begin{array}{l}\text { Government sponsored research programs: IV.6 "Computeri- } \\
\text { zation of the Ministry of Education and Higher Learning" and } \\
\text { RI.14 "Computerization of Institutions of Higher Learning." }\end{array}$ \\
\hline 1978 & Work on MSK, the inter-university computer network, begins. \\
\hline 1981 & $\begin{array}{l}\text { Polish Association of Informatics (Polskie Towarzystwo } \\
\text { Informatyczne) formed, which publishes a computer journal } \\
{[20] \text {. }}\end{array}$ \\
\hline 1981-1983 & MSK (Gliwice, Warsaw, Wroclaw) functional, based on X.25. \\
\hline 1983 & $\begin{array}{l}\text { Meritum computer produced in Poland; reverse-engineered } \\
\text { from the TRS- } 80 \text { and able to run its software. }\end{array}$ \\
\hline 1985 & Bajtek computer magazine begins publication. \\
\hline 1986 & $\begin{array}{l}\text { CPBR } 8.13 \text { "Building a National Academic Computer Net- } \\
\text { work - KASK." Project culminates in } 1990 \text { with the connec- } \\
\text { tion to EARN. }\end{array}$ \\
\hline 1987 & First FidoNet connections made to Poland [21] \\
\hline 1988-1989 & $\begin{array}{l}\text { DECnet connections between Solarski in Gliwice and } \\
\text { Cyfronet in Krakow. }\end{array}$ \\
\hline 1990 & $\begin{array}{l}\text { CoCom lifts most of its restrictions on the sale of computer } \\
\text { equipment, telecommunications equipment, and precise mill- } \\
\text { ing machines to former communist countries. Poland's } \\
\text { PLEARN will be able to connect to European Academic Re- } \\
\text { search Network (EARN, the European BITNET). } \\
\text { A leased line is established between CERN and the Kraków } \\
\text { Institute of Nuclear Physics (IFJ); first email sent from Poland } \\
\text { from the IFJ [22]. }\end{array}$ \\
\hline 1991 & $\begin{array}{l}\text { NASK, established by Warsaw University, connects to } \\
\text { NSFNET; on } 17 \text { August the first TCP/IP packets are sent from } \\
\text { Physics department at Warsaw University to the computer } \\
\text { center at Copenhagen University [22]. }\end{array}$ \\
\hline
\end{tabular}

Fig. 1. Important dates leading to the first TCP/IP connection to Poland

In 1988, the first effort to connect BITNET to Poland came from the high-energy physicists. This community, which was accustomed to working in international groups, had enjoyed using BITNET while working abroad "and felt very handicapped without it at home" [23]. They desired to set up a local network connection to SASK, the Warsaw branch of KASK, with the hope that their counterparts in other countries might eventually help to connect them to BITNET. With the support of the university hierarchy, the physicists leveraged their contacts, both with BITNET in the United States and inside the Polish government. 


\section{$4 \quad$ Networks in Poland}

The myth of the computerization of Poland after the fall of the Iron Curtain also neglects prior work that was done. The earliest observations of the project had to do with how quickly Poland was able to connect to the Internet after the loosening of CoCom restrictions. It seemed unlikely that without any previous effort Poland could have so suddenly connected to the Internet within months of getting access to western computing and networking technology and then within two years have been able to put down the infrastructure necessary to connect many of its major cities to the Internet. COCOM actually seems to have been more of a political catalyst in Poland's connection to the Internet, rather than a technical one.

The credit for the technical underpinnings of Poland's connection to the Internet seems instead to lie with the scarcely mentioned academic networks. A number of early networks were found, but the earliest identified was the Miedzyuczelniana SiecKomputerowa (MSK, or the Inter-university Computer Network), whose efforts eventually evolved into Krajowa Academicka Siec Komputerowa, (KASK, or the National Academic Computer Network).

As seen in Figure 1, MSK and the Warsaw localized Akademicka Siec Komputerowa (ASK, or the Academic Computer Network) stemmed from government research topics IV.6 "Computerization of the Ministry of Education and Higher Learning" (mgr inz. Andrzej Zienkiewicz, UW) and RI.14 "Computerization of Institutions of Higher Learning" (dr inz. M. Bazewicz, PWr), which were proposed between 1977 and 1978. Work on MSK began in 1978; however, at the time the engineers who were working on MSK were unaware of ISO documentation on the Open Systems Interconnection (OSI) model. Fascinatingly, for its pilot program, MSK connected the Centrum Obliczeniowe Politechniki Wroclawskiej (Computation Centre of the Technical University of Wroclaw), the Osrodek Elektronicznej Techniki Obliczeniowej Politechniki Slaskiej (Electronic Computing Technology Centre of the Technical University of Slask), and at the Centrum Obliczeniowe Instytutu Podstaw Informatyki (Centre of Electronic Computing Technology at the Institute of the Fundamentals of Information Technology) in Warsaw. Within this pilot configuration there were two sub nodes in Wroclaw, an Odra 1305 and a R32; one in Warsaw, an Odra 1305; and one in Gliwice, an Odra 1305 as well.

Warsaw, Wroclaw, and Gliwice were chosen as the initial nodes in the MSK not only because these cities contained well-respected universities that possessed the necessary computer resources to take part, but also because of the existing telephone line infrastructure between the cities. Of course, with the expected expansion of MSK into KASK, plans to connect numerous other cities were already made, namely to connect Krakow, Katowice, Poznan, Torun, Bydgoszcz, and Gdansk. In addition to connecting new cities there were also intentions to connect more and more subnodes within the cities, allowing more universities to join the network, and beyond that, there were also hopes for establishing a direct link between the Warsaw node and the 


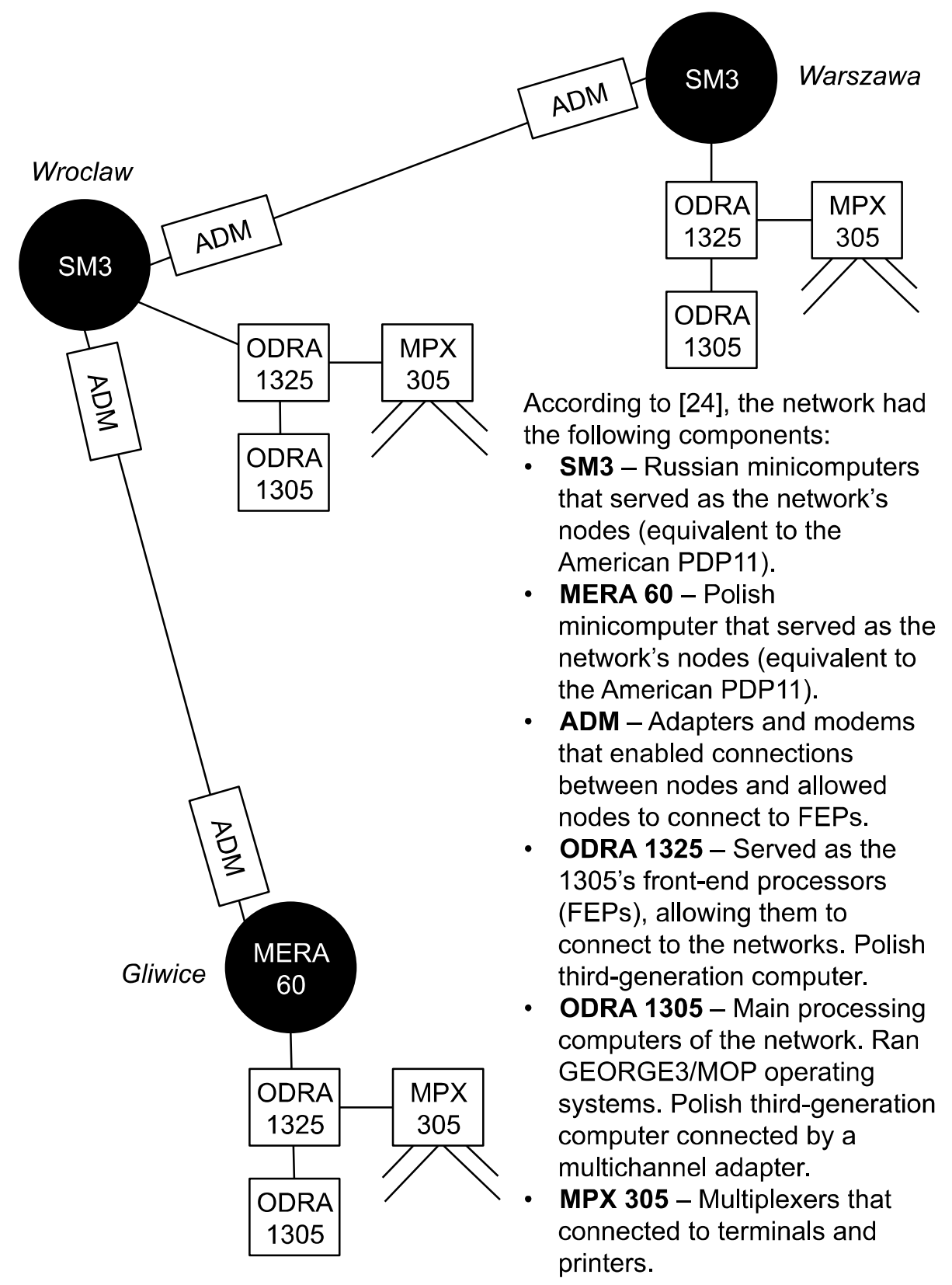

Fig. 2. Initial Hardware of the Inter-University Academic Network

Gliwice node. From these aspirations, it is clear that Polish engineers were moving ahead with their own networks and making sizable strides in spreading their network across Poland. 
For the most part, the early academic networks, such as MSK, were seen as purely academic endeavors by both the Polish authorities and many of the academics who made use of them. Within its pilot stage, MSK allowed users to access data bases within the processing computers from any connected terminal, to send collections of data between any two processing computers, run programs available on any of the processing computers on any given terminal, and communicate between terminals.

\section{$5 \quad$ Standards and Connections}

Despite the fact that the early Polish academic networks were developed behind the isolative barrier of CoCom, connection to outside networks came about quite rapidly once the political situation allowed organizations like EARN to grant Poland connection to their networks. This was in no small part thanks to the mindset of the engineers behind networks like MSK. While ISO documentation on networks was unknown to the engineers behind MSK at the start of their project, in order to one day connect to the international community the engineers went through the substantial effort of restarting their work to have MSK follow the standards set by ISO [25].

At the start of MSK, the engineers were basing their work on the data link protocol ISO HDLC (High Level Data Link Control) and INWG 96, a transfer protocol that guaranteed datagram transfer. Despite a lack of access to the latest in western computing equipment, Polish engineers found equivalent hardware for their networks in their own Odra and Mera computers or Soviet SM3s. Work on MSK began in 1978; however, at the time the engineers were unaware of the effort by the International Organization for Standardization (ISO) renewed effort to define data protocols. Although the concepts behind TCP/IP reach as far back as 1973 in INWG 39, their implementation was not yet fully developed in 1975 when INWG 96 was released. Despite the agreement on INGW 96, DARPA broke off, at this point, stating that the were "too close to completing implementation of the updated INWG 39" [26]. Nevertheless, the rest of the international community had come to a consensus to move away from TCP/IP towards a model that would better manage bandwidth allocation.

Fascinatingly, once the engineers found out about the documentation they restarted their work on the network in order to have it meet international standards, implying that the engineers intended to make a network that would be able to connect to the rest of the world when the political situation allowed. After becoming acquainted with ISO documentation on the OSI model and the CCIT documentation pertinent to the first three layers, the conception of MSK was shifted in a direction that would maximize agreement with the OSI model [25]. Poland's decision to move away from the datagram model to the more moderated model of OSI may seem counterproductive if we are comparing their networks to today's internet; however, at the time the international community was moving away from TCP/IP, considering it to be a temporary experiment [27]. Poland's switch to an OSI model does point to a desire and effort to stand with the international community and move towards a model that would, in the future, best be able to interact with other academic networks abroad. 


\section{Computers and the Underground}

Poland's rich computer culture has been documented elsewhere, but it is worthwhile to note that the first local personal (micro) computer produced began production in 1983, the Meritum, which was reverse-engineered from the Tandy corporation's TRS80, released in the U.S. in 1977. In collaboration with Bajtek, a Polish computer magazine founded in 1985, the Polish Boy Scout association broadcast programs over FM radio in BASIC that users would record on cassettes and load into their computers [22]. Other examples of selling western computers on the so-called informal market abound.

Computers in Poland and Hungary were commonly used at home, and PCs played an important role in producing and distributing bibuta (the Polish version of the Russian samizdat). A covert program, which [28] calls "the best-kept secret of all the CIA's Cold War operations" (429), smuggled printing presses, radios, computers, Telex machines, and the first fax machines to Poland to help the Solidarity movement. In addition, computers were used to "organize the boycotts and evaluate data" concerning the election results (462). The Solidarity paper Tygodnik Mazowsze, which started as an underground journal, was produced on a PC and printed on a laser printer [18], [29].

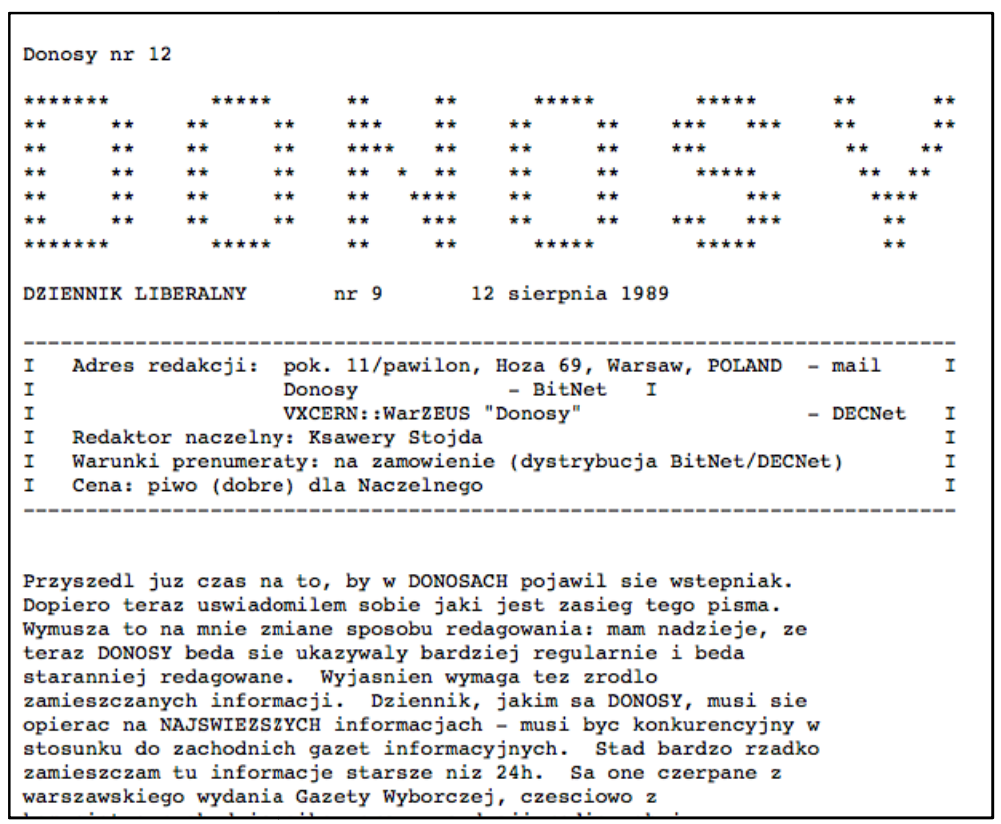

Fig. 3. Donosy E-Newspaper

Being seen purely as tools to enhance academic capabilities within the fields of physics and astronomy, the academic networks largely escaped any monitoring of use. Thus, the networks created a uniquely safe environment, where academics, or at least 
those who wished, could communicate freely amongst themselves about topics that strayed from academia into something closer to political criticism and dissent. A prominent example of dissenting expression within such an environment is Donosy (Fig. 3), the first Polish digital newspaper, which originated within the Warsaw University's Physics department in 1989. In August, this daily newspaper in e-mail format gathered uncensored news and rumors from a variety of sources, and also published information about salaries and pricing, reprinted letters to the editors, and made reflections on current events. The return addresses indicate that Donosy was distributed via BITNET and DECNet.

\section{Conclusion}

The thesis that significant investments in network research and implementation were necessary on national levels in order for the Internet to spread to Poland as quickly as it did provides an important insight into the ethics of innovation. Myths about the Internet being created by the U.S. in isolation and diffusing to other countries effortlessly suggests that ideas succeed on their own merits. The theory that information technology spread easily into Poland once political blocks were eased is satisfying in some ways, but in fact does not tell the entire story. Technology transfer is dependent upon the work of many individuals in the target area, and it is these users who have as much to do with the innovation's success as do the innovators. The story of facile technology transfer seems to suggest that a good idea will diffuse on its own accord, so the only responsibility of an innovator is to develop a good idea. A more nuanced story is needed so that future innovators recognize how technologies depend upon a user base that is ready and able to take advantage of it.

This story also demonstrates the fact that what might seem to be innovation for the sake of innovation was a success in Poland. The story of the 20th century is sometimes told as one of the loss of disinterested scientists who no longer were able to follow their curiosity. As shown by [30], however, this is not an entirely accurate portrait. In fact, it would seem as if there has been plenty of time and effort dedicated to amateur and disinterested pursuits. The story in Poland demonstrates how this effort paid off. Even while scientists had no way of knowing that the Cold War was drawing to a close, they continued in isolation to innovate and explore current ideas in computer networking. This effort paid off unexpectedly when they were able to join the TCP/IP Internet, in much the same way one would expect the disinterested inquiry of science to pay off in unforeseen ways.

Finally, this story points toward the importance of international standards organizations such as ISO. This is not to be expected, given that the story of TCP/IP is generally told as "standards war" in which the ISO's OSI protocols failed. As much as the success of TCP/IP seems to be a triumph over the failed OSI standards, the story of Poland seems to indicate that the story needs to be told differently. Even as political barriers prevented trade in high technology goods, access to international standards allowed Polish engineers to independently create computers and networks that would eventually be able to connect to the rest of the world. 
Acknowledgement. The authors are indebted to the Undergraduate Summer Research Program and its founder, Associate Dean Iraj M. Kalkhoran, at the New York University Polytechnic Institute of Technology, which provided Patrick Gryczka with a stipend that supported this research.

\section{References}

1. Naughton, J.: A Brief History of the Future: From Radio Days to Internet Years in a Lifetime. Overlook Press, Woodstock (2000)

2. Segaller, S.: Nerds 2.0.1: A Brief History of the Internet. TV Books, New York (1998)

3. Leslie, C.: Competing Histories of Technology: Recognizing the Vital Role of International Scientific Communities behind the Innovation of the Internet. In: Tatnall, A., Blyth, T., Johnson, R. (eds.) HC 2013. IFIP AICT, vol. 416, pp. 196-206. Springer, Heidelberg (2013)

4. Hannemyr, G.: The Internet as Hyperbole: A Critical Examination of Adoption Rates. The Information Society 19(2), 111-121 (2003)

5. John, N.A.: The Diffusion of the Internet to Israel: the First 10 Years. Israel Affairs 17(3), 327-340 (2011)

6. Budd, R.: IBM and Polish Universities Create Computer-Network (June 11, 1991)

7. Hooper, L.: Poland Moves Toward Leading Role In Computerization of Eastern Europe. Wall Street Journal: A7H (December 2, 1991)

8. Cortada, J.W.: Patterns and Practices in How Information Technology Spread around the World. IEEE Annals of the History of Computing 20(4), 4-25 (2008)

9. Phillips, D.: Chronicle. Pigulki 6 (June 5, 1991), http://ftp.icm.edu.pl/packages/pigulki/pigulki6.pub (accessed March 19, 2014)

10. Smereczynski, A.: One Year of EARN Networking in Poland. Pigulki 6 (June 5, 1991), http://ftp.icm.edu.pl/packages/pigulki/pigulki6.pub (accessed March 19, 2014)

11. Cain, F.: Computers and the Cold War: United States Restrictions on the Export of Computers to the Soviet Union and Communist China. Journal of Contemporary History 40, 131-147 (2005)

12. Lewis, P.: Allies Curb Computers for Soviet. New York Times, Late Edition (East Coast): D7 (July 17, 1984)

13. Naumann, F.: Abakus zum Internet: Die Geschicte der Informatik. Primus Verlag, Darmstadt (2001)

14. Grassmuck, V.: Internet (2008), http: / /www.hgb-leipzig.de/ vgrass / semi-mediengesch/10_internet.html (accessed January 5, 2014)

15. Kalle, C.: Das Internet in Deutschland - Ein alter Hut? Kompass 64 (July 18, 1995), http://mikro-berlin.org/Events/os/reftexte/kalle/0InetinDland.html (January 5, 2014)

16. Hofmokl, T.: Academic Networks in Central and Eastern Europe (2008), http: / / www. ceenet.org/ceenet_cbyc_anicaee.html (accessed April 5, 2009)

17. Binczewski, A., Mazurek, C., Meyer, N., Niwinski, S., Stroinski, M.: Perspektywy Rozwoju Sieci POL-34/155. Sieci Komputerowe w Badaniach Naukowych (n.d.)

18. Geipel, G.L., Tomasz Jarmoszko, A., Goodman, S.E.: The Information Technologies and East European Societies. East European Politics \& Societies 5(3), 394-438 (1991) 
19. Stozek, J.: FidoNet in Poland. Pigulki 6 (June 5, 1991), http: / / ftp.icm. edu.pl/ packages /pigulki/pigulki6.pub (accessed March 19, 2014)

20. Wasiak, P.: Computing behind the Iron Curtain: Social Impact of Home Computers in the Polish People's Republic. Tensions of Europe \& Inventing Europe Working Paper Series (2010), http: / /www. tensionsofeurope.eu/www/en/files/-get/ publications/WP_2010_08_Wasiak.pdf (accessed March 18, 2014)

21. Daniels, D.: IFNA Welcomes Poland to FidoNet. FidoNews: International FidoNet Association Newsletter 4(34) (1987)

22. Baran, D.: Polish Internet at the End of the 20th Century. In: Pokorna-Ignatowicz, K. (ed.) The Polish Media System 1989-2011, pp. 41-51. Krakow Society for Education (2012)

23. Gajewski, J.: Polish Bitnet: How It All Started. Pigulki 6 (June 5, 1991), http://ftp.icm.edu.pl/packages/pigulki/pigulki6.pub (accessed March 19, 2014)

24. Janyszek, J.: Dziesieciolecie Dzialalnosci Wroclawskiego Centrum SieciowoSuperkomputerowego 1995-2005. WCSS, Wroclaw (2005)

25. Bilski, E.: Protokoly w Miedzyuczelnianej Sieci Komputerowj. Wydawnictwo Politechniki Wroclawskiej, Wroclaw (1987)

26. McKenzie, A.: INWG and the Conception of the Internet: An Eyewitness Account. IEEE Annals of the History of Computing 33(1), 66-71 (2011)

27. Abbate, J.: Inventing the Internet. MIT Press, Cambridge (1999)

28. Fischer, B.B.: Solidarity, the CIA, and Western Technology. International Journal of Intelligence and Counter Intelligence 25(3), 427-469 (2012)

29. Diehl, J.: In Moscow and Warsaw, Official and Unofficial Press Playing New Roles; Solidarity Weekly Evolves in Scope, Sophistication. The Washington Post: A13 (April 4, 1987)

30. Shapin, S.: The Scientific Life. Chicago University Press, Chicago (2008) 